\title{
A test of risk vulnerability in the wider population
}

\author{
Philomena M. Bacon ${ }^{1} \cdot$ Anna Conte $^{2}(\mathbb{D}) \cdot$ Peter G. Moffatt $^{1}{ }^{1}$
}

Published online: 7 June 2019

(c) The Author(s) 2019

\begin{abstract}
Panel data from the German SOEP is used to test for risk vulnerability (RV) in the wider population. Two different survey responses are analysed: the response to the question about willingness-to-take risk in general and the chosen investment in a hypothetical lottery. A convenient indicator of background risk is the VDAX index, an established measure of volatility in the German stock market. This is used as an explanatory variable in conjunction with HDAX, the stock market index, which proxies wealth. The impacts of these measures on risk attitude are identifiable by exploiting the time dimension of the panel and matching survey months with corresponding observations from these time-varying factors. Both of the survey responses allow us to test for decreasing absolute risk aversion (DARA); in one case, we find strong evidence of DARA, while in the other, we do not. Both survey responses also allow us to test for $\mathrm{RV}$, and in both cases we find strong evidence. In the case of the hypothetical lottery response, we are also able to estimate a "coefficient of risk vulnerability" (CRV). This is defined as the absolute amount by which absolute risk aversion rises in response to a doubling of background risk. We estimate CRV to be between 1.03 and 1.27.
\end{abstract}

Keywords Risk vulnerability $\cdot$ Background risk $\cdot$ Panel data $\cdot$ Survey data

We acknowledge access to the German Socio-Economic Panel (SOEP) for use in this research under licence number: 2596.

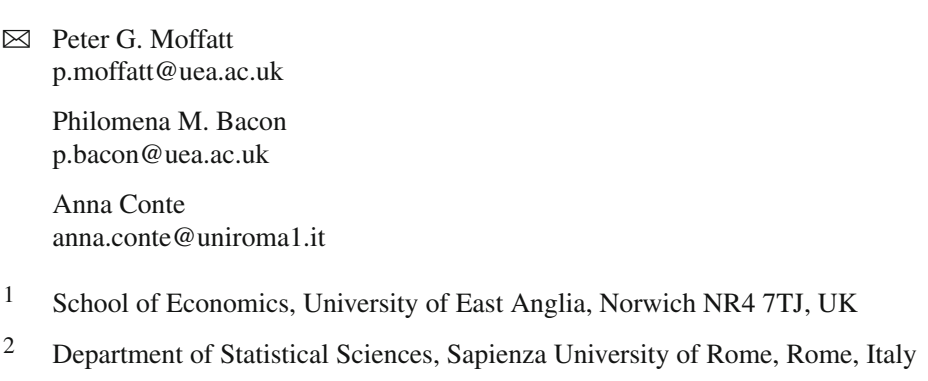




\section{Introduction}

There is much empirical evidence of decreasing absolute risk aversion (DARA), the phenomenon of an individual becoming more willing to take risk when their wealth increases by an absolute amount. This evidence comes from both the field (e.g. Hamal and Anderson 1982) and the laboratory (e.g. Levy 1994). A related concept is risk vulnerability (RV) (Gollier and Pratt 1996). This is the phenomenon of an individual becoming less willing to take risk when mean-zero background risk (independent of other risks) is added to their wealth.

Risk vulnerability is an important hypothesis, especially in the light of the 2008 global financial crisis, and the global recession that followed. The period of (and immediately following) the crisis amounted to a textbook example of a period of abnormally high background risk. It is important to understand the impact of this on individuals' risk attitude in order to gain greater insight into our understanding of the overall impact of the crisis for future reference. It has been shown, for example, that risk-vulnerable agents respond to an increase in background risk by adjusting their portfolio in favour of safe assets and by demanding more insurance (Gollier and Pratt 1996). Risk Vulnerability has even been put forward as an explanation for the well-known equity premium puzzle (Mehra and Prescott 1985; Weil 1992).

In many theoretical studies, RV is assumed. For example, Heaton and Lucas (2000) invoke the assumption in their explanations of portfolio puzzles. However, perhaps surprisingly, there is comparatively little empirical evidence of RV.

Experimental evidence of RV has been found by Beaud and Willinger (2015), Lusk and Coble (2008) and others. In this paper, we instead use survey data drawn from the wider population. It may be argued that in the present context survey data have considerable advantages over experimental data with regard to external validity. Aside from the standard advantages of a larger and more representative sample, it is reasonable to expect that measures of background risk that might be used in the context of survey data (e.g. measures of macroeconomic uncertainty) have greater external validity than the types of background risk typically induced in a laboratory setting.

Guiso and Paiella (2008) find evidence of RV from a cross section sample of Italian individuals, where the chosen measure of background risk is the variance (over time) in per-capita GDP in the individual's province of residence. West and Worthington (2014) estimate the impact of macroeconomic conditions on risk attitude using an Australian panel data set. Although they do not explicitly refer to background risk and RV, our analysis is similar to theirs in respect of exploiting a panel data set, and introducing time-varying factors.

The panel data we use is the German Socio-Economic Panel (SOEP). This consists of repeated data on a large number of individuals. We focus on two outcome variables. The first is the response to the direct question about willingness to take risks in general. This response is provided on a 0-10 Likert scale (Likert 1932). Hence, the random effects ordered probit model is used for the analysis of this outcome. The second outcome is the response to a hypothetical lottery investment question. An individual's response to this question may be taken to imply that that individual's coefficient of absolute risk aversion lies in a particular interval. Consequently, the random effects interval regression model is used for the analysis of this outcome. 
In order to test for DARA and RV, we match repeated responses to these riskrelated questions in the panel, to observations (from the month immediately preceding the survey date) on the time-varying factors, HDAX and VDAX. HDAX is the German stock market index, which acts as a proxy for wealth, and hence, a test of the impact of HDAX on risk attitude amounts to a test of DARA. VDAX is an established indicator of volatility in the German stock market, ${ }^{1}$ thereby having a direct interpretation as a measure of background risk prevailing in any given time period. Consequently, a test of the impact of VDAX on risk attitude may be interpreted as a test of RV.

In addition to testing for risk vulnerability in the manner described above, we will go a step further by deducing an estimate of the "coefficient of risk vulnerability" (CRV), which will be defined in due course. To our knowledge, this is the first attempt at the empirical quantification of risk vulnerability.

The paper is organized as follows: Sect. 2 describes the data; Sect. 3 discusses the modelling strategies; Sect. 4 reports and discusses the results, and also constructs an estimate of the CRV; and Sect. 5 concludes.

\section{The SOEP data set}

The German Socio-Economic Panel Survey (SOEP) has been running since 1984 and surveys a cohort of approximately 20,000 households annually, inquiring into lifestyle and economic activities (Frick et al. 2007; Jürgen and Gert 2007). ${ }^{2}$ In 2004, the survey broadened to include the first questions associated with risk attitude.

What we will refer to as the "general risk question" was repeated biennially until 2008 after which it was asked annually, with the last observation considered in the research being in 2012. The "general risk question" is given by:

How do you see yourself? Are you generally a person who is fully prepared to take risks or do you try to avoid taking risks? Please tick a box on the scale, where 0 means "risk averse" and the value 10 means "fully prepared to take risks"

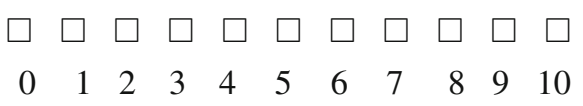

For the sake of homogeneity, we consider head-of-households only. The resulting sample consists of 11,903 individuals observed an average of 3.68 times each. Histograms of the general risk response for each year separately are presented in Fig. 1. The most interesting feature of these histograms is the changing shape of the distribution of responses between years. In 2004 and 2006, it appears that the distribution

\footnotetext{
1 More specifically, the VDAX represents the expected volatility of the DAX index in the next 30 days. The equivalent of VDAX in the US stock market is the well-known VIX, which is also known as the "fear index".

2 For details of the target population, the sampling strategy, and the methods of ensuring representativeness, see: https://soep.readthedocs.io/en/latest/overview/sample.html.
} 


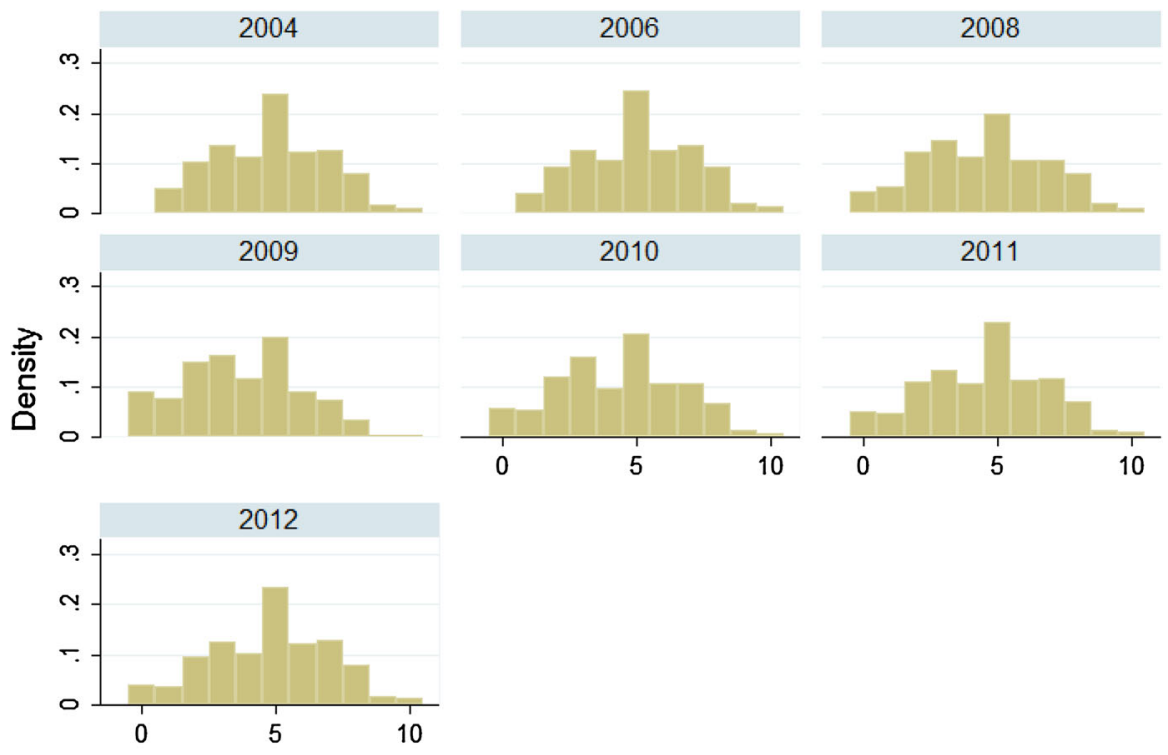

Graphs by Survey Year

Fig. 1 Distribution of self-reported risk attitude (household head)

is fairly symmetric around the midpoint of 5, roughly implying risk neutrality. In 2008, 2009, and 2010, however, there is a definite sense that the distribution is more concentrated on the lower half, implying a tendency to risk aversion. These years, of course, correspond to the global recession which followed the 2008 global financial crisis. The asymmetry is seen most clearly in 2009 , and this is not surprising since 2009 is considered to be the nadir of the crisis. In 2011 and 2012, we see an apparent return to symmetry, and the distribution for 2012 appears surprisingly similar to the pre-crisis distributions seen in 2004 and 2006. Since the impact of the crisis on the response is exactly the sort of effect in which we are most interested, repeated responses over this particular set of years appear ideal for testing the hypothesis of RV.

Data on responses to the general risk question forms the focus of our first model described in Sect. 3.1 below.

The second question that is of interest to us is the "hypothetical lottery question". The question takes the following form:

Imagine that you have won $€ 100,000$ in the lottery. Immediately after receiving your winnings you receive the following offer: You have the chance to double your money. But it is equally possible that you will lose half the amount invested. You can participate by staking all or part of your $€ 100,000$ on the lottery, or choose not to participate at all. What portion of your lottery winnings are you prepared to stake on this financially risky, yet potentially lucrative lottery investment?

$€ 100,000$ (i.e. all of it); 


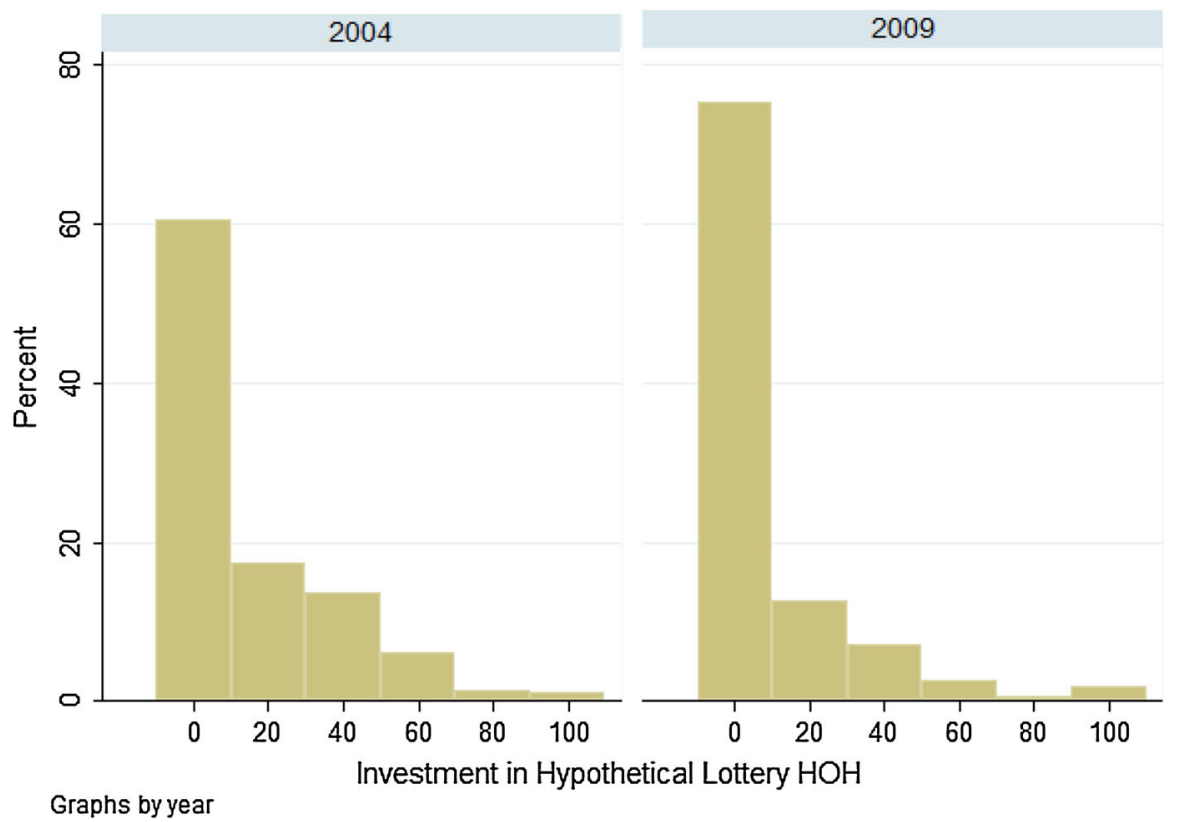

Fig. 2 Distribution of response to hypothetical lottery question

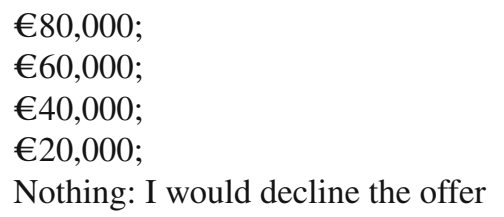

The hypothetical lottery question was asked only twice, in 2004 and in 2009. Histograms of responses for these two years are shown in Fig. 2. Again it is illuminating to compare the histograms between years. In both cases, we see a mode at the choice of a zero investment, implying risk aversion. However, this mode appears much more prominent in 2009 than in 2004, and again it is reasonable to hypothesize that this is a consequence of 2009 coinciding with the nadir of the global recession that followed the financial crisis.

Data on responses to the hypothetical lottery question form the focus of our second model which is described in Sect. 3.2. The Spearman correlation coefficient between the two responses (self-reported risk attitude and investment in hypothetical lottery) is +0.2596 , with a $p$-value of 0.0000 . The implied consistency between the two responses is a useful basis for data validation.

From the SOEP data, we also extract a number of demographic variables which are used as explanatory variables in the two models. ${ }^{3}$ These include age, gender, marital

\footnotetext{
${ }_{3}$ Demographic variables are obtained from the longitudinal SOEPv 29 files: SOEP pl_en and SOEP pequiv_en.
} 

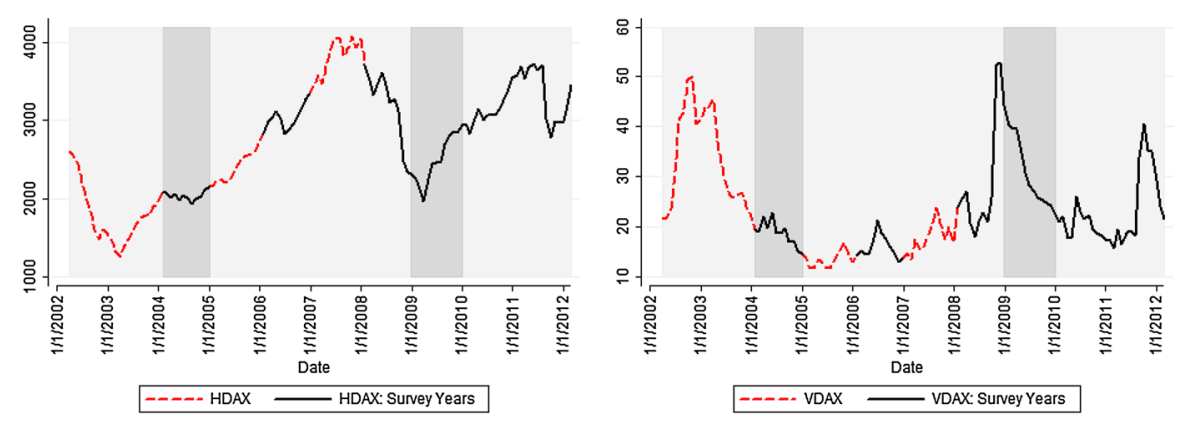

Fig. 3 HDAX, Stock market index (left panel), and VDAX, Stock market volatility (right panel), over time. Source: datastream. Solid sections of the lines represent periods in which data on responses to the general risk question are available; the shaded vertical bars represent the periods in which the hypothetical lottery question was asked

status, and years of education. Descriptive statistics of all variables used, along with SOEP dataset codes, are supplied in Table 4 of the Appendix.

As mentioned in Sect. 1, the financial variables we use are the German stock market index (HDAX) and the German stock market volatility index (VDAX). ${ }^{4}$ The former may be considered a suitable proxy for wealth, while the latter is a proxy for the prevailing level of background risk. ${ }^{5}$ In Fig. 3, we present time series plots of these two variables (HDAX, left panel, and VDAX, right panel). The solid sections of the lines represent years in which data on responses to the general risk question are available; the shaded bars represent periods in which the hypothetical lottery question was asked. The most important features of these plots are the steep fall in HDAX and the even steeper rise in VDAX that coincide with the onset of the global financial crisis in 2008.

Linking together the observations made from the two time series graphs (Fig. 3) with those from the two histograms of response data (Figs. 1, 2) leads directly to the two testable hypotheses that are the focus of this paper. A positive effect of HDAX on willingness to take risk (or a negative effect on absolute risk aversion) will amount to evidence of DARA. A negative effect of VDAX on willingness to take risk (or a positive effect on absolute risk aversion) will amount to evidence of RV.

\section{Modelling strategies}

In this section, we shall develop modelling strategies for the responses to the two risk-related survey questions presented and discussed in Sect. 2.

\footnotetext{
${ }^{4}$ Monthly data on HDAX and VDAX are obtained from Datastream.

5 We refer to VDAX as a proxy for background risk, because clearly not all individuals hold their wealth in the form of common stock, on which VDAX is based. We nevertheless consider it to be a useful proxy on the basis that it captures the level of uncertainty in the macroeconomy as generally perceived by economic agents.
} 


\subsection{General risk attitude: model 1}

For responses to the general risk question, we shall use the random effects ordered probit model, which is outlined as follows. ${ }^{6}$ Let $i$ index respondent, $i=1, \ldots, n$, and let $t$ index time period, $t=1, \ldots, T$. Let $y_{i t}$ be respondent $i$ 's response to the general risk question about risk taking in period $t$, and assume that this can take one of the integer values $1,2,3, \ldots, J$. Let $y_{i t}^{*}\left(-\infty<y_{i t}^{*}<+\infty\right)$ be the underlying latent variable representing respondent $i$ 's propensity to risk taking in period $t$. Let $x_{i t}$ be a vector of characteristics relevant in explaining the risk attitude of respondent $i$ at time $t$. Let $z_{t}$ be a vector of financial variables. The random effects ordered probit model is based on the assumption that $y_{i t}^{*}$ depends linearly on $x_{i t}$ and $z_{t}$, according to:

$$
\begin{aligned}
& y_{i t}^{*}=x_{i t}^{\prime} \beta+z_{t}^{\prime} \gamma+u_{i}+\epsilon_{i t} \\
& u_{i} \sim N\left(0, \sigma_{u}^{2}\right), \quad \epsilon_{i t} \sim N(0,1) i=1, \ldots, n, \quad t=1, \ldots T .
\end{aligned}
$$

$\beta$ and $\gamma$ are vectors of parameters; neither contains an intercept. There are two stochastic terms: the individual-specific term $u_{i}$ and the random error term $\epsilon_{i t}$. Note that these are both assumed to be normally distributed with mean zero; the variance of $u_{i}$ is a free parameter, while the variance of $\epsilon_{i t}$ is, for identification, normalized to 1 . This normalization is required in order to set the otherwise arbitrary scale of the latent variable $y^{*}$. The latent variable $y^{*}$ is linked to the observed variable $y$ via a set of $J-1$ cut-point parameters, which are estimated along with the other parameters.

We will be particularly interested in the elements of $\gamma$. The parameter estimate associated with HDAX (resp. VDAX) will enable us to test DARA (resp. RV).

\subsection{The hypothetical lottery question: Model 2}

For responses to the hypothetical lottery question, we shall use the random effects interval regression model, which is outlined as follows. ${ }^{7}$

We will assume that each individual has the Constant Absolute Risk Aversion (CARA) utility function:

$$
U(x)=1-\exp (-r x) \quad-\infty<r<\infty ; \quad x>0
$$

so that the individual's coefficient of absolute risk aversion is $r$. Recall from Sect. 2 that the hypothetical lottery question requires respondents to choose one of six possible "investments" in a particular lottery. ${ }^{8}$ It is easily established using (2) that (assuming

\footnotetext{
6 For further details of the random effects ordered probit model, see Greene and Hensher (2010, chapter 9). Maximum likelihood estimation of its parameters may be obtained using the xtoprobit command available in STATA (StataCorp 2017).

7 The interval regression approach is similar in many ways to the ordered probit approach outlined in Sect. 3.1. One important difference is that in the former, the cut-points defining the intervals are known numbers, while in the latter, the cut-points are unknown and are therefore parameters to be estimated.

${ }^{8}$ Please refer back to Sect. 2 for a description of the lottery.
} 
Table 1 Ranges of coefficient of absolute risk aversion $(r)$ implied by different investment choices in hypothetical lottery question, assuming expected utility maximization

\begin{tabular}{lll}
\hline Investment & $r$ Lower & $r$ Upper \\
\hline$€ 100,000$ & $-\infty$ & 0.50 \\
$€ 80,000$ & 0.50 & 0.70 \\
$€ 60,000$ & 0.70 & 0.95 \\
$€ 40,000$ & 0.95 & 1.50 \\
$€ 20,000$ & 1.50 & 4.70 \\
$€ 0$ & 4.70 & $\infty$ \\
\hline
\end{tabular}

expected utility maximization) each of the six possible investment choices implies a range for $r$, and the limits of these ranges are presented in Table 1.9

As in Sect. 3.1, let $i$ index respondent, $i=1, \ldots, n$, and let $t$ index time period, $t=1, \ldots, T$. For respondent $i$ in period $t$ let $y_{i t}$ be the investment choice and let $r_{i t}$ be the coefficient of absolute risk aversion. Since observations on $y_{i t}$ imply intervals for $r_{i t}$, we model the variable $r_{i t}$ as follows.

$$
\begin{aligned}
& r_{i t}=x_{i t}^{\prime} \beta+z_{t}^{\prime} \gamma+u_{i}+\epsilon_{i t} \quad i=1, \ldots, n ; \quad t=1, \ldots, T \\
& u_{i} \sim N\left(0, \sigma_{u}^{2}\right) ; \epsilon_{i t} \sim N\left(0, \sigma_{\epsilon}^{2}\right)
\end{aligned}
$$

The relationship between the observed investment choice $y_{i t}$ and the (latent) risk attitude variable $r_{i t}$ is (using the values from Table 1):

$$
\begin{gathered}
y_{i t}=100,000 \Rightarrow \quad-\infty<r_{i t} \leq 0.50 \\
y_{i t}=80,000 \Rightarrow 0.50<r_{i t} \leq 0.70 \\
y_{i t}=60,000 \Rightarrow 0.70<r_{i t} \leq 0.95 \\
y_{i t}=40,000 \Rightarrow 0.95<r_{i t} \leq 1.50 \\
y_{i t}=20,000 \Rightarrow 1.50<r_{i t} \leq 4.70 \\
y_{i t}=0 \quad \Rightarrow \quad 4.70<r_{i t} \leq \infty
\end{gathered}
$$

(3) and (4) together define the random effects interval regression model whose parameters may be estimated using Maximum likelihood. ${ }^{10}$

With reference to (3), the risk attitude for respondent $i$ at time $t, r_{i t}$, depends on the respondent's characteristics, contained in $x_{i t}$, and also on financial variables as pertaining at time $t$, contained in $z_{t}$. Once again, we are interested in the elements of $\gamma$. In particular, let $\gamma_{v}$ be the coefficient associated with the logarithm of our background

\footnotetext{
9 To understand where the numbers in Table 1 come from, consider the first row. For simplicity, let us measure money amounts in units of $€ 100,000$. If a respondent indicates that they would invest the entire $€ 100,000$, they are opting for a 50:50 gamble between 0.5 units and 2 units, and the expected utility of this gamble is $1-0.5 \exp (-0.5 r)-0.5 \exp (-2 r)$. If they instead chose the next riskiest investment of $€ 80,000$, they are opting for a 50:50 gamble between 0.6 units and 1.8 units, with expected utility $1-0.5 \exp (-0.6 r)-0.5 \exp (-1.8 r)$. The value of $r$ that equalizes these two expected utilities is 0.50 . Hence, anyone whose CARA parameter is less than 0.50 will invest $€ 100,000$, while anyone whose CARA is greater than 0.50 will invest a smaller amount. This explains the upper limit of 0.50 appearing in the first row of Table 1. Numbers appearing in other rows are obtained using similar reasoning.

10 Using the xtintreg command in STATA (StataCorp 2017).
} 
risk measure, VDAX. If we define the coefficient of risk vulnerability (CRV) to be the absolute change in absolute risk aversion resulting from a doubling of background risk, then ${ }^{11}$

$$
\mathrm{CRV}=\gamma_{v} \log (2)
$$

An estimate of CRV, defined in (5), will be obtained in the next section.

\section{Results}

In this section, estimation results are presented and discussed.

\subsection{Testing for risk vulnerability using self-reported risk attitude}

In Table 2, we present results from the application of the random effects ordered probit model, described in Sect. 3.1, to panel data on self-reported willingness to take (general) risk. Model 1 in Table 2 explains the response purely in terms of demographic characteristics of the individual, and the effect of each of these variables is strongly significant. In particular, we see a greater propensity to take risks by younger, more highlyeducated, unmarried, males. These findings are in agreement with previous research using the same data source on the determinants of risk attitude (Dohmen et al. 2011).

Model 2 in Table 2 includes an income/wealth variable in the form of the logarithm of income from asset flows. This variable has a strongly positive effect on the propensity to take risk, and this result is consistent with decreasing absolute risk aversion (DARA).

Model 3 in Table 2 includes the two financial variables $\log (\operatorname{HDAX})_{-1}$ and $\log (\mathrm{VDAX})_{-1}$, respectively, the logarithm of the two indices HDAX and VDAX in the month previous to the month of the interview. ${ }^{12}$ As explained previously, HDAX is included to capture the effect of changes in wealth, while VDAX captures the effect of changes in background risk. The strongly positive coefficient on HDAX therefore amounts to further evidence of DARA. The strongly negative effect of VDAX indicates that individuals are less willing to take risks at times when the stock market is more volatile. Treating stock market volatility as a measure of background risk, this result may be interpreted as strong evidence of risk vulnerability (RV).

Finally, Model 4 includes some additional variables, $y$ and $y^{2}$, which represent a year trend and a squared year trend, and year-specific month-trends (i.e. variables that take the value 1 in January, 2 in February, and so on for a specific year) and their square. The inclusion of these variables is motivated by concern that the two variables of central attention, HDAX and VDAX, are by their time series nature, fixed within a month. Consequently, all respondents interviewed in a particular month have the same values

\footnotetext{
11 To understand (5), assume that $r=\alpha+\beta \log v$ and suppose that $v$ doubles from $v$ to $2 v$. Before this change, the value of $r$ is $\alpha+\beta \log v$ and after the change it is $\alpha+\beta \log 2 v=\alpha+\beta \ln v+\beta \log 2$. The change in $r$ resulting from the doubling of $v$ is therefore $\beta \log 2$.

12 Note that since the two indices HDAX and VDAX are observed at the end of each month, it is logical to use the previous month's values as the basis for decisions in the current month.
} 
Table 2 Random effects ordered probit results (cut-points estimates not reported)

\begin{tabular}{|c|c|c|c|c|}
\hline General risk & Model 1 & Model 2 & Model 3 & Model 4 \\
\hline Male & $\begin{array}{l}0.488 * * * \\
(0.0163)\end{array}$ & $\begin{array}{l}0.485 * * * \\
(0.0163)\end{array}$ & $\begin{array}{l}0.489 * * * \\
(0.0166)\end{array}$ & $\begin{array}{l}0.488 * * * \\
(0.0167)\end{array}$ \\
\hline Married & $\begin{array}{l}-0.0671 * * * \\
(0.0140)\end{array}$ & $\begin{array}{l}-0.0750 * * * \\
(0.0141)\end{array}$ & $\begin{array}{l}-0.0776 * * * \\
(0.0143)\end{array}$ & $\begin{array}{l}-0.0806 * * * \\
(0.0143)\end{array}$ \\
\hline Age & $\begin{array}{l}-0.0186 * * * \\
(0.000445)\end{array}$ & $\begin{array}{l}-0.0189 * * * \\
(0.000447)\end{array}$ & $\begin{array}{l}-0.0185 * * * \\
(0.000461)\end{array}$ & $\begin{array}{l}-0.0179 * * * \\
(0.00047)\end{array}$ \\
\hline \# Years of education & $\begin{array}{l}0.0312 * * * \\
(0.00254)\end{array}$ & $\begin{array}{l}0.0288 * * * \\
(0.00259)\end{array}$ & $\begin{array}{l}0.0301 * * * \\
(0.00263)\end{array}$ & $\begin{array}{l}0.0316 * * * \\
(0.00265)\end{array}$ \\
\hline Log (income asset flows) & & $\begin{array}{l}0.00965 * * * \\
(0.00202)\end{array}$ & $\begin{array}{l}0.0102 * * * \\
(0.00204)\end{array}$ & $\begin{array}{l}0.0104 * * * \\
(0.00205)\end{array}$ \\
\hline $\log \left(\mathrm{HDAX}_{-1}\right.$ & & & $\begin{array}{l}0.0589 * * \\
(0.0223)\end{array}$ & $\begin{array}{l}0.3113 * * \\
(0.1221)\end{array}$ \\
\hline $\log (\mathrm{VDAX})_{-1}$ & & & $\begin{array}{l}-0.646 * * * \\
(0.0148)\end{array}$ & $\begin{array}{l}-0.272 * * * \\
(0.0515)\end{array}$ \\
\hline$y$ & & & & $\begin{array}{l}-0.298 * * * \\
(0.037)\end{array}$ \\
\hline$y^{2}$ & & & & $\begin{array}{l}0.0272 * * * \\
(0.0034)\end{array}$ \\
\hline Linear and quadratic & No & No & No & Yes \\
\hline Year-specific month-trends & & & & \\
\hline$\sigma_{u}$ & $\begin{array}{l}0.937 * * * \\
(0.008)\end{array}$ & $\begin{array}{l}0.936 * * * \\
(0.008)\end{array}$ & $\begin{array}{l}0.959 * * * \\
(0.008)\end{array}$ & $\begin{array}{l}0.963 * * * \\
(0.008)\end{array}$ \\
\hline$n$ & 21,911 & 21,911 & 21,911 & 21,911 \\
\hline$T$ (mean of) & 3.7 & 3.7 & 3.7 & 3.7 \\
\hline Log-likelihood & $-162,823.46$ & $-162,812.08$ & $-161,566.44$ & $-160,906.79$ \\
\hline
\end{tabular}

Dep. var.: Willingness to take risks (Likert scale 0-10, over 2004-2012)

Standard errors in parentheses. $* p<0.05, * * p<0.01, * * * p<0.001$

for each of these variables. This may be viewed as a version of the classic Moulton problem (1986). The standard solution to this problem is to allow "cluster-specific" effects. Since the clusters in this case are time periods, including year trends and year-specific month-trends allows for the required month effects in a way that also allows for time series structure of the data. Although this causes some coefficients to change in value from Model 3, the key conclusions (in particular strong evidence of RV) do not change.

\subsection{Testing for risk vulnerability using hypothetical lottery choice}

We now turn to the results from estimating Eq. (3) using the random effects interval regression model, as explained in Sect. 3.2. Recall that the underlying latent variable in this model is the respondent's coefficient of absolute risk aversion. Hence we expect the coefficient estimates in this model to be of opposite signs to the corresponding 
Table 3 Random effects interval regression using investment choices in hypothetical lottery

\begin{tabular}{|c|c|c|c|}
\hline & Model 1 & Model 2 & Model 3 \\
\hline Male & $\begin{array}{l}-0.877 * * * \\
(0.0664)\end{array}$ & $\begin{array}{l}-0.8412 * * * \\
(0.0660)\end{array}$ & $\begin{array}{l}-0.7926 * * * \\
(0.0656)\end{array}$ \\
\hline Married & $\begin{array}{l}01383 * \\
(0.0641)\end{array}$ & $\begin{array}{l}0.2699 * * * \\
(0.0647)\end{array}$ & $\begin{array}{l}0.3150 * * * \\
(0.0641)\end{array}$ \\
\hline Age & $\begin{array}{l}0.0492 * * * \\
(0.00194)\end{array}$ & $\begin{array}{l}0.0528 * * * \\
(0.00196)\end{array}$ & $\begin{array}{l}0.0477 * * * \\
(0.0020)\end{array}$ \\
\hline \# Years of education & $\begin{array}{l}-0.1607 * * * \\
(0.0102)\end{array}$ & $\begin{array}{l}-0.125 * * * \\
(0.0105)\end{array}$ & $\begin{array}{l}-0.1346 * * * \\
(0.0105)\end{array}$ \\
\hline Log (income asset flows) & & $\begin{array}{l}-0.1424 * * * \\
(0.0114)\end{array}$ & $\begin{array}{l}-0.1357 * * * \\
(0.0113)\end{array}$ \\
\hline $\log \left(\mathrm{HDAX}_{-1}\right.$ & & & $\begin{array}{l}2.8234 * * * \\
(0.3402)\end{array}$ \\
\hline $\log (\operatorname{VDAX})_{-1}$ & & & $\begin{array}{l}1.6557 * * * \\
(0.0902)\end{array}$ \\
\hline Constant & $\begin{array}{l}6.1296 * * * \\
(0.166)\end{array}$ & $\begin{array}{l}6.129 * * * \\
(0.1664)\end{array}$ & $\begin{array}{l}-20.6948 * * * \\
(2.5200)\end{array}$ \\
\hline$\sigma_{u}$ & $\begin{array}{l}1.8957 * * * \\
(0.0562)\end{array}$ & $\begin{array}{l}1.857 * * * \\
(0.0566)\end{array}$ & $\begin{array}{l}1.953 * * * \\
(0.0532)\end{array}$ \\
\hline$\sigma_{e}$ & $\begin{array}{l}2.997 * * * \\
(0.0277)\end{array}$ & $\begin{array}{l}2.998 * * * \\
(0.0276)\end{array}$ & $\begin{array}{l}2.862 * * * \\
(0.0287)\end{array}$ \\
\hline$n$ & 23,448 & 23,448 & 23,488 \\
\hline$T$ (mean of) & 1.5 & 1.5 & 1.5 \\
\hline Log-likelihood & $-26,620.072$ & $-26,541.034$ & $-26,246.513$ \\
\hline
\end{tabular}

Dep. var.: Coefficient of absolute risk aversion $(r)$

left censored $=340 ;$ right censored $=15,973 ;$ interval $=7126$.

Standard errors in parentheses. $* p<0.05, * * p<0.01, * * * p<0.001$

estimates reported in Table 2 (since the latent variable underlying that model was willingness to take risk).

The results of the random effects interval regression model are reported in Table 3. Again we start with a base specification (Model 1) in which only characteristics of the respondent are included. The signs of each of these effects are consistent with those in Table 2 and with results elsewhere in the literature.

The second specification (Model 2) is one which includes a measure of individual wealth, in the form of the logarithm of income from assets. As expected, this has a strongly negative effect, implying decreasing absolute risk aversion (DARA).

Finally, Model 3 includes the two financial variables $\log (\mathrm{HDAX})_{-1}$ and $\log (\mathrm{VDAX})_{-1}$. $\log (\mathrm{HDAX})_{-1}$ appears to have a strongly positive effect on risk aversion. This can only be seen as an unexpected result. Given the role of HDAX as a proxy for wealth, decreasing absolute risk aversion leads to the prediction that the coefficient of $\log \left(\mathrm{HDAX}_{-1}\right.$ in this model will be negative. However, note that the coefficient of asset income is still strongly negative, suggesting that asset income is 
successfully performing the role of a wealth proxy, while we must look elsewhere for the source of the positive effect of HDAX. ${ }^{13}$

Once again the coefficient of $\log (\mathrm{VDAX})_{-1}$ is consistent with the hypothesis of risk vulnerability: $\log (\mathrm{VDAX})_{-1}$ has a strongly positive effect on risk aversion. If we apply (5) to the coefficient of +1.66 , we obtain a coefficient of risk vulnerability (CRV) of +1.15 , with a $95 \%$ confidence interval of $(1.03,1.27) .{ }^{14}$ The point estimate is interpreted as follows. If background risk doubles, as it appeared to do at the onset of the global financial crisis (see Fig. 3, right panel), a typical agent's coefficient of absolute risk aversion is expected to rise by an amount 1.15 .

\section{Conclusion}

We have used two very different survey questions from the German SOEP to test for risk vulnerability (RV). The first is self-reported risk attitude, and the second is investment choice in a hypothetical lottery. We applied a nonparametric test to establish that the two measures have a positive association in the sample. Analysis of the two outcomes has called for the use of two different econometric models: random effects ordered probit and random effects interval regression. Our chosen measure of background risk is the VDAX, which represents the level of volatility in the German stock market. In both estimations, the effect of this variable is strongly significant with a sign consistent with RV.

Given our objective of testing RV, it has been particularly useful to have used data from a time period (2004-2012) that includes what is now widely recognized to be a period of higher-than-normal background risk, the 2008 global financial crisis.

We have defined a coefficient of risk vulnerability (CRV) that can be estimated empirically, and we are not aware of any previous attempts to quantify RV. Using the hypothetical lottery choice data, we have obtained an estimate of CRV of 1.15. The $95 \%$ confidence interval for CRV of $(1.03,1.27)$, being far from zero and reasonably narrow, indicates firstly that a typical agent does indeed display RV, and secondly that $\mathrm{CRV}$ is being estimated with admirable precision.

Open Access This article is distributed under the terms of the Creative Commons Attribution 4.0 International License (http://creativecommons.org/licenses/by/4.0/), which permits unrestricted use, distribution, and reproduction in any medium, provided you give appropriate credit to the original author(s) and the source, provide a link to the Creative Commons license, and indicate if changes were made.

\section{Appendix: Summary statistics}

\section{See Table 4.}

\footnotetext{
13 In order to address the Moulton problem, we have used an approach similar to the one explained in the previous section. However, in this case, none of year-specific month-trends improved the fit with respect to Model 3. The results are available from the authors on request.

14 The $95 \%$ confidence interval is obtained as the point estimate \pm 1.96 standard errors. In accordance with (5), the standard error of the estimate of CRV is simply obtained by multiplying the relevant standard error from Table 3 by $\ln (2)$.
} 


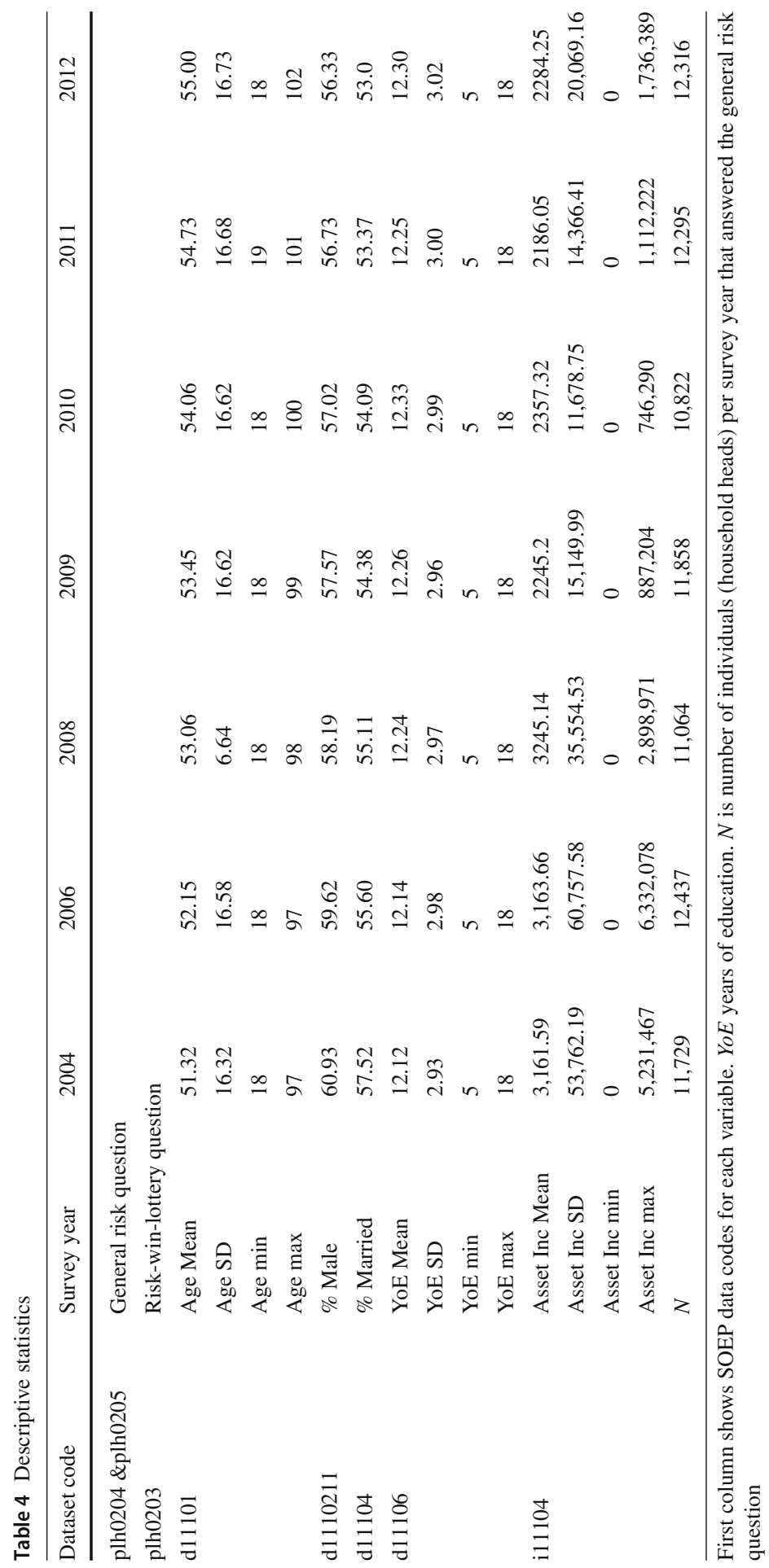




\section{References}

Beaud, M., \& Willinger, M. (2015). Are people risk vulnerable? Management Science, 61(3), 624-636.

Dohmen, T. J., Falk, A., Huffmann, D., Schupp, J., \& Wagner, G. (2011). Individual risk attitudes: Measurement, determinants, and behavioral consequences. Journal of the European Economic Association, 9(3), 522-550.

Frick, J. R., Jenkins, S. P., Lillard, D. R., Lipps, O., \& Wooden, M. (2007). The cross-national equivalent file CNEF and its member country household panel studies. Schmollers Jahrbuch, 127(4), 627-654.

Gollier, C., \& Pratt, John, W. (1996). Risk vulnerability and the tempering effect of background risk. Econometrica, 64(5), 1109-1123.

Greene, W. H., \& Hensher, D. A. (2010). Modeling Ordered Choices: A Primer. Cambridge: Cambridge University Press.

Guiso, L., \& Paiella, M. (2008). Risk aversion, wealth and background risk. Journal of the European Economic Association, 6(6), 1109-1150.

Hamal, K., \& Anderson, J. R. (1982). A note on decreasing absolute risk aversion among farmers in Nepal. Australian Journal of Agricultural Economics, 26(3), 220-225.

Heaton, J., \& Lucas, D. (2000). Portfolio choice in the presence of background risk. The Economic Journal, $110(460), 1-26$.

Jürgen, S., \& Gert, W. (2007). 'The German Socio-Economic Panel Study (SOEP): Scope. SOEP papers on Multidisciplinary Panel Data Research: Evolution and Enhancements'.

Levy, H. (1994). Absolute and relative risk aversion: An experimental study. Journal of Risk and Uncertainty, 8(3), 289-307.

Likert, R. (1932). A Technique for the Measurement of Attitudes (Vol. 140). Archives of Psychology: Columbia University Press, New York.

Lusk, J. L., \& Coble, K. H. (2008). Risk aversion in the presence of background risk: Evidence from an economic experiment. Risk Aversion in Experiments, 12, 315-340.

Mehra, R., \& Prescott, E. (1985). The equity premium: A puzzle. Journal of Monetary Economics, 15(2), $145-161$.

Moulton, B. (1986). Random group effects and the precision of regression estimates. Journal of Econometrics, 32(3), 385-97.

StataCorp (2017). Stata Statistical Software: Release 15. College Station TX: Stata Corp LLC.

Weil, P. (1992). Equilibrium asset prices with undiversifiable labor income risk. Journal of Economic Dynamics and Control, 16(3), 769-790.

West, T. \& Worthington, Andrew, C., (2014). Macroeconomic conditions and Australian financial risk attitudes, 2001-2010. Journal of Family and Economic Issues, 35(2), 263-277.

Publisher's Note Springer Nature remains neutral with regard to jurisdictional claims in published maps and institutional affiliations. 